\title{
The Effects of Online Reviews of Opinion Leaders on Users' Investment Intentions in Virtual Financial Communities
}

\author{
Yunxia Shi ${ }^{1}$, Chunhao $\mathrm{Ma}^{1}$, Xinxin Bao ${ }^{1}$, Wenpei Wei ${ }^{1}$ \\ ${ }^{1}$ Shandong Technology and Business University, Yantai, Shandong, China \\ Correspondence: Chunhao Ma, Shandong Technology and Business University, No.191, Laishan District, Yantai \\ City, Shandong Province, China.
}

Received: December 24, 2019

Accepted: January 30, $2020 \quad$ Online Published: February 10, 2020

doi:10.5539/ibr.v13n3p39

URL: https://doi.org/10.5539/ibr.v13n3p39

\begin{abstract}
With the rapid development of internet financial community, more and more people opt to obtain financial information through online reviews. Based on the perspective of online reviews of opinion leaders, we explored the influences of online reviews of opinion leaders on users' investment intentions in the financial community. We introduced the concepts of user trust and online interaction propensity and built a theoretical model. Our results, based on data collected from 205 users of a famous financial virtual community, suggested that the online reviews of opinion leaders had a significant effect on users' investment intentions. In conclusion, financial institutions should pay attention to opinion leaders and enhance communication and relationships with them.
\end{abstract}

Keywords: opinion leader, virtual finance community, online interaction propensity, user trust, investment intention

\section{Introduction}

Due to rapid developments in internet and information technology, the 'virtual communities in different themes' emerged. Each year, the numbers of financial virtual community users has increased (Frank, 2001). Therefore, exploiting this market that has a potentially huge consumption ability may possibly solve the current problem of lacking of new customers faced by financial institutions (Zhou, 2010). However, most research studies in the internet finance community has been conducted from the perspective of the overall macro environment and financial institutions. There is limited research conducted from the perspective of users.

Current research shows that users' investment intentions are influenced by positive recommendation and word-of-mouth opinions from relevant reference groups (Park, Lee, \& Han, 2007). However, in the internet era, users' investment intentions are influenced by information obtained from internet finance (Zhou, 2010). Increasingly, virtual financial communities are becoming the main source and communication channel of information (Kim, Lee, \& Hiemstra, 2004). Research studies have shown that opinion leaders not only occupy a central position in the virtual community but also have a strong influence on changing others' mind (Van, 2011). Beside this, opinion leaders are highly effective when working in small, strong-tie groups (Moldovan, Muller, Richter, \& Yom-Tov, 2016). As a key reference group, opinion leaders in the virtual financial community play an important role in providing word-of-mouth opinions and recommendations ( Bansal, \& Voyer, 2000). How then, do the online reviews of opinion leaders, as the most important form of word-of-mouth communication, affect users' investment intentions? This study, conducted from an online review of perspectives of opinion leaders', explores the mechanism through which online reviews of opinion leaders influence users' investment intentions in financial virtual community by introducing the concepts of user trust and online interaction propensity.

\section{Literature Review and Research Hypotheses}

\subsection{Opinion Leader's Online Reviews and User Trust}

As one of the most important sources of word-of-mouth information, online reviews are the products of service assessment information submitted by consumers via the internet (Ludwig, 2013.) Online reviews have increasingly become a popular and important source of information for people searching for relevant products or service information (Du, 2016). Park, Lee and Han (2007) point out that online reviews can help consumers identify suitable products for their needs. Bei, Chen and Widdows (2004) believe that online reviews are similar to traditional word-of-mouth opinions that recommend a product or seller to potential consumers. Prior to 
purchasing financial products or services, many people opt to obtain information from online reviews ( Dellarocas, Zhang, \& Awad, 2007).

Lazarsfeld first used the concept of 'opinion leader' in their Two-stage Communication Theory proposed in 1948 (Lazarsfeld, Berelson, \& Gaudet, 1948). An opinion leader is an active person who often provides information to others and plays an important role in the process of information communication (Chen, \&Liu, 2015). Van (2011) illustrated that opinion leaders are at a central position in a society or group. Bagozzi and Dholakia (2002) believed that the emergence and development of virtual communities has largely changed traditional business functions. Of late, there is an increase in the number of consumers attempting to obtain information about products and services. Research by Bodendorf and Kaiser (2009) illustrated that opinion leaders in virtual communities are usually at the center of the online community. Conversely, Pavlou and Gefen (2004) found that consumers' trust and satisfaction would only increase with an increase in the quality of information availed to them. Nevertheless, the online reviews of opinion leaders' tends to deliver high quality information (Choi, 2015). Hence, in the financial virtual community, opinion leaders' online reviews are more influential than the online reviews of other users because reviews from opinion leaders are easier to recognize and can be trusted.

Thus, we hypothesized:

H1: The online reviews of opinion leaders' have a positive impact on user trust.

\subsection{User Trust and User's Investment Intention}

Many scholars define trust as a belief, confidence or expectation that others will fully consider your opinions and make a solid promise. Gefen, Karahanna and Straub (2003) constructed models and pointed out through empirical research that trust has an important impact on consumers' purchasing intentions. Alsajjan and Dennis (2008) also confirmed that trust can affect consumers' attitudes and intentions to engage in certain behavior. Investment intentions could be regarded as a form of consumer behavior, and therefore it could be affected by trust. On the other hand, Awad and Ragowsky (2008) showed that the lack of trust was a key main reason for failure of online transactions.

Thus, we hypothesized:

H2: User trust has a positive impact on their investment intention.

H3: User trust mediates between the online reviews of opinion leaders and users' investment intention

\subsection{Opinion Leader's Online Reviews and User's Investment Intention}

Relevant research shows that opinion leaders usually have expertise and skills in a certain field or several fields (Chen, 2015). The online reviews of opinion leaders in virtual financial communities are of high quality, direct and interesting (Luqiu, 2019). They contain original content, are of high-quality with profound insights and are frequently published and viewed. As one of the sources of information relied on by users, opinion leaders often influence the views and cognition of others (Weimann, 1994). Some studies have shown that online reviews are inherently provocative and affect conversion rates for consumers and investors (Ludwig, 2013). To sum up, the online reviews of opinion leaders may have an impact on users' investment intentions in the virtual financial community.

Thus, we hypothesize:

H4: Online reviews of opinion leaders have a positive impact on users' investment intentions.

\subsection{The Moderating Effect of Online Interaction Propensity}

Online interaction propensity is defined as the general tendency of a member to interact in an online environment with people they have never met in-person (Zaichkowsky ,1986; Wierz \& de Ruyter, 2007).

Blazevic et al. (2014) noted the existence of a relationship between online interaction propensity, and the provision of information and advice to other members. Dessart (2017) also showed that there was a positive relationship between online interaction propensity and carrying out some behaviors, such as the communicating and sharing of ideas with others.

Under a high online interaction propensity, users will carefully assess the ability, integrity, trustworthiness and other characteristics of opinion leaders. They will then form a certain rational cognition, that generates trust in these online reviews( Dong, Zhang, 2009). Under the low online interaction propensity, users' motivation to finely process online reviews will be weakened and it will not be easy to generate trust.

Thus, we hypothesize: 
H5: Online interaction propensity plays a moderating role between online reviews of opinion leaders and users' trust.

To sum up, the assumptions of this model are shown in figure 1 :

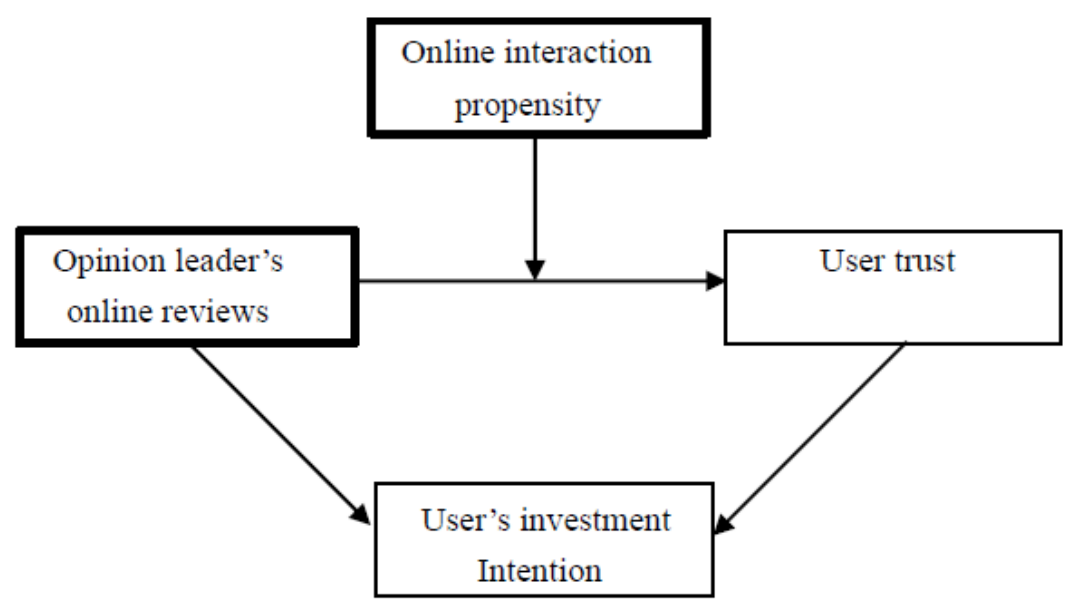

Figure 1. Hypothetical model

\section{Research Design and Methodology}

\subsection{Research Object and Sample Structure}

Table 1. Sample structure

\begin{tabular}{|c|c|c|c|}
\hline Category & Characteristics & Number & Percentage \\
\hline \multirow[t]{2}{*}{ Gender } & Male & 122 & 59.5 \\
\hline & Female & 83 & 40.5 \\
\hline \multirow[t]{4}{*}{ Age } & 18 and below & 42 & 20.5 \\
\hline & 19 to 29 & 91 & 44.4 \\
\hline & 30 to 39 & 64 & 31.2 \\
\hline & 40 and above & 8 & 3.9 \\
\hline \multirow[t]{3}{*}{ Educational background } & Below high school & 72 & 35.1 \\
\hline & University & 101 & 49.3 \\
\hline & Master or above & 32 & 15.6 \\
\hline
\end{tabular}

Based on a literature review, a questionnaire survey was adopted as the data source. We choose some financial virtual communities, such as financial BBS, to distribute questionnaires to. Online community members are more active than real community members. Online questionnaire survey not overcomes the limitation of region and expands the scope of research, but also eases obtaining feedback from respondents (Wan ,2014). In order to minimize the influence of common method deviation on the research results, we selected relatively mature scales during questionnaire design, and scale items were translated based on existing Chinese expressions.

A total of 274 questionnaires were collected. After eliminating invalid questionnaires, 205 questionnaires were left with an effective recovery rate of $74.8 \%$. The specific sample structure is shown in table 1 .

\subsection{Scale Design}

The scales used in this study were mature and their reliability had been established. In order to contextualize each scale to China, we used reverse translation to translate the original scale. Then some questionnaires were piloted. We then adjusted the items according to the 32 validated questionnaires. The questionnaire adopted a Likert's five-point scale.

Online reviews are one type of online word-of-mouth sources of information (Bei, 2004). Therefore, an established scale of online reviews of opinion leaders refers to the research results of Thakur (Thakur, Angriawan, \& Summey, 2015). The scale of user trust mainly refers to the works of McKight and Choudhury (McKnight \& Choudhury, 2006). The scale of online interaction propensity refers to research done by Casalo (Casalo, 2011). The scale of investment intention mainly refers to Li and Wang's research study (Li \& Wang, 2016).

\section{Data Analysis}

We analyzed the collected data using SPSS 21.0. 


\subsection{Reliability and Validity Analysis}

To ensure the reliability of the results, CFA was used to test the reliability and validity of the scale. As shown in table 2, Cronbach's alpha coefficient of all factors was above 0.8, indicating that the scale was reliable. Both KMO and Bartlett sphericity tests attained statistical significance, indicating that all the scales had high credibility and internal consistency. The combined reliability of each latent variable was around 0.9 , and the scale had a good construction validity. AVE values of all variables were greater than 0.5 , indicating that all the scales had good convergent validity.

Table 2. Reliability and validity test results of the scale

\begin{tabular}{ccccc}
\hline variable & KMO & Cronbach's alpha & CR & AVE \\
\hline OLOR & 0.889 & 0.898 & 0.8993 & 0.5307 \\
UT & 0.745 & 0.902 & 0.9541 & 0.6161 \\
OIP & 0.672 & 0.871 & 0.9429 & 0.6827 \\
UII & 0.670 & 0.827 & 0.8944 & 0.6297 \\
\hline
\end{tabular}

Note: $\mathrm{OLOR}=$ opinion leader's online reviews, UT=user trust, $\mathrm{OIP}=$ online interaction propensity, UII $=$ user's investment intention.

\subsection{Descriptive Statistical Analysis}

The descriptive statistical analysis results of each variable are shown in table 3 . The values in the diagonal brackets are the root mean square of AVE. The correlation coefficient between some variables was high, indicating the possibility of multicollinearity between some variables. Thus, the Variance Inflation Factor Diagnostic method was used to test the possible multicollinearity to ensure accurate model estimation. The VIF values of each variable were: OLOR 2.904, UT 2.698, OIP 4.345. They were all below the critical level that indicated the absence of multicollinearity in the model.

As shown in table 3, there was a significant positive correlation between OLOR and UT as well as between OLOR and UII $(\beta=0.534,0.488, p<0.01)$. There was a significant positive correlation between UT and UII $(\beta=0.763, \mathrm{p}<0.01$. $)$ and between OIP and UT $(\beta=0.617, \mathrm{p}<0.01)$. Thus, the research hypotheses were preliminarily verified.

Table 3. Correlation coefficients between variables

\begin{tabular}{|c|c|c|c|c|c|c|}
\hline Variable & $\mathrm{M}$ & SD & 1 & 2 & 3 & 4 \\
\hline 1.OLOR & 3.86 & 0.69 & $(0.73)$ & & & \\
\hline 2.OIP & 3.76 & 0.79 & $0.609^{* * *}$ & $(0.82)$ & & \\
\hline 3.UT & 3.72 & 0.78 & $0.534^{* *}$ & $0.617^{* *}$ & $(0.78)$ & \\
\hline 4.UII & 3.61 & 0.89 & $0.488^{* * *}$ & $0.547^{* *}$ & $0.763^{* * *}$ & (0.79) \\
\hline
\end{tabular}

\subsection{Model Hypothesis Test}

According to Wen's suggestion, we used hierarchical regression for the test. (Wen, 2005) The hierarchical regression method was used to test hypotheses and the test results are shown in table 4 .

Table 4. Regression analysis results of hypothesis testing

\begin{tabular}{|c|c|c|c|c|c|}
\hline Variable & $\begin{array}{c}\text { UT } \\
\text { Model1 }\end{array}$ & $\begin{array}{c}\text { UT } \\
\text { Model2 }\end{array}$ & $\begin{array}{c}\text { UT } \\
\text { Model3 }\end{array}$ & $\begin{array}{c}\text { UII } \\
\text { Model4 }\end{array}$ & $\begin{array}{c}\text { UII } \\
\text { Model5 }\end{array}$ \\
\hline Gender & 0.484 & 0.437 & 0.435 & $-0.092^{*}$ & $0.194 * *$ \\
\hline Age & 0.014 & -0.011 & -0.012 & 0.144 & $0.302 *$ \\
\hline OLOR & $0.692^{* *}$ & $0.327^{* * *}$ & $0.482^{* * *}$ & $0.607^{* *}$ & $0.131^{* * *}$ \\
\hline $\begin{array}{l}\text { UT } \\
\text { OIP }\end{array}$ & & $0.484^{* * *}$ & $0.485^{* * *}$ & & $0.687^{* *}$ \\
\hline OLOR $\times$ OIP & & & $0.005^{*}$ & & \\
\hline $\begin{array}{c}\mathrm{R}^{2} \\
\Delta \mathrm{R}^{2}\end{array}$ & 0.443 & $\begin{array}{l}0.629 \\
0.187\end{array}$ & $\begin{array}{l}0.630 \\
0.116\end{array}$ & 0.422 & $\begin{array}{l}0.672 \\
0.250\end{array}$ \\
\hline
\end{tabular}

Note: ${ }^{* *}, *$ indicate significance levels of .05 and .10 , respectively. OLOR $=$ opinion leader's online reviews, $\mathrm{UT}=$ user trust, $\mathrm{OIP}=$ online interaction propensity, $\mathrm{UII}=$ user's investment intention.

We first centralized all the data and constructed the interaction terms using the product of OLOR and OIP.

Model 1 examined the role of independent variables. It showed that OLOR had a significant positive effect on UT $(\beta=0.692, p<0.01)$, and H1 was verified. Wen's Mediation Test Method was used to explore whether UT played an intermediary role between OLOR and UII. OLOR and UT were included in the regression equation. 
As can be seen from model 4 and model 5 in table 4, the direct effect of OLOR on dependent variable UII was significant $(\beta=0.607, \mathrm{p}<0.01)$. When the mediating variable UT was added, the influence coefficient became $0.131(\mathrm{p}<0.01)$. The positive effect of the mediator variable UT on the dependent variable UII was still significant $(\beta=0.687, p<0.01)$. It showed that user trust partly mediated the influence of the online reviews of opinion leader on users' investment intentions. $\mathrm{H} 2$ and $\mathrm{H} 3$ were verified. The standard regression coefficient of OLOR to UII was $0.607(\mathrm{p}<0.01)$, which showed that online reviews of opinion leaders had a significant positive impact on users' investment intentions. Thus, H4 was verified. In table 4, model 1 to 3 tested the moderating effect of OIP. Model 2 added OIP as the moderator variable based on model 1. The results show that OIP had a significant effect on UT. Based on model 2, model 4 included the interaction terms of the independent variable OLOR and the moderator variable OIP. Regression results showed that interaction terms had a significant impact on user trust $(\beta=0.005, \mathrm{p}<0.05)$. It indicated that the online interaction propensity moderated the relationship between opinion leader's online reviews and users' investment intentions. Thus, H5 was verified.

According to the methods provided by Aiken and West (1991), the moderating effect diagram shown in figure 2 was drawn to explore the intensity of the moderating effect at different OIP levels. OIP level played a facilitating role in the positive relationship between OLOR and UT. In other words, users with a high online interaction propensity were more sensitive to the online reviews of opinion leaders and tended to generate more trust.

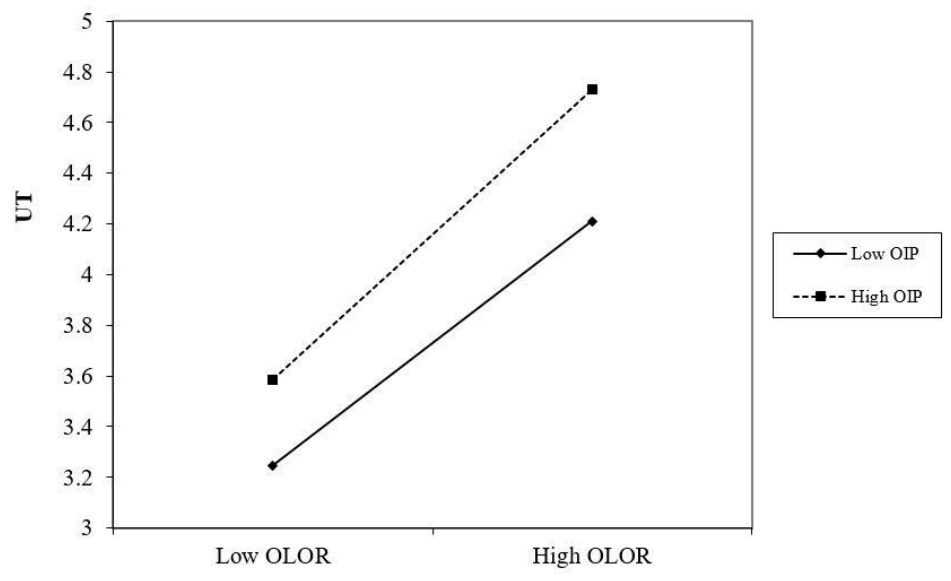

Figure 2. Moderating effect diagram

\section{Results and Discussion}

Previously, research on the investment intention of virtual financial community users' focused on the macro-financial environment, financial institutions and intermediary organizations (Li \& Xue, 2019; Lin, Bruning, \& Swarna, 2018). We studied the influence of the reviews of opinion leaders on users' investment intentions from the perspective of the users. This expanded the research field on investment in the Internet era. This paper contributes to exploring the mechanism by which the reviews of opinion leaders impacts on the potential investment intention in virtual communities. The main conclusions are presented subsequently.

Firstly, the online reviews of opinion leader has a positive impact on a user's investment intention. In the Internet era, virtual financial communities are increasingly providing more financial information to users. Opinion leaders are at the center of the virtual financial community and therefore spread a great deal of information due to their influence. Opinion leaders play the role of information dissemination as their online reviews is a channel for information communication. This financial information can easily be understood and accepted by users by secondarily processing opinion leaders' own attitudes, purposes and values. By virtue of their origin, profession, interests and other characteristics, opinion leaders make users have an impression on the quality of information, and thus affects users' investment intentions.

Secondly, user trust plays a partial intermediary role between the online reviews of opinion leaders and users' investment intentions. The online reviews of opinion leaders not only directly influence users' investment intentions, but also indirectly influences it by influencing the trust of users. Opinion leaders, who are trusted by users, often are accorded more right to air their opinions. Their online reviews are more persuasive and credible than those of opinion leaders who are not trusted. This users' trust will subsequently have a significant positive impact on users' investment intentions. 
Thirdly, the online interaction propensity plays a positive moderating role between online reviews of opinion leaders and users' trust. We found that users with a high degree of online interaction propensity tended to trust the online reviews of opinion leaders. This may further generate investment intention. In other words, online interactions propensity tended to have a positive effect on the generation of trust among users.

\subsection{Management Enlightenment}

This paper brings lots of enlightenment to financial institutions. First of all, relevant financial institutions should enhance their contact with opinion leaders and increasingly consider whether the current channels of information dissemination can be conveniently accessed by opinion leaders. Relevant financial institutions should pay attention to the value of opinion leaders. When making decisions, relevant institutions should defer to the views of opinion leaders in time to modify and adjust some of their investment strategies (Zuo, Wang, \& Fan, 2014). It's important to invest money to establish cooperative relations with more opinion leaders and in turn match opinion leaders to the brands of financial institutions to improve the brand image. Bearing in mind the importance of trust, on the one hand, financial institutions should establish cooperative relationships with opinion leaders that are trusted by users. On the other hand, opinion leaders themselves should also reflect on how to improve user trust in the reviews of opinion leaders and attempt to increase users' trust. Financial institutions and opinion leaders should pay more attention to users with a high degree of online interaction and exploit their investment potential. Because they are more likely to generate trust, they are more likely to generate intention to invest. Opinion leaders should focus on online interactions with these users and deliver more financial information to them.

\subsection{Limitations and Prospects}

Despite our best efforts to ensure the validity and accuracy of this study, some limitations were inevitable. Firstly, only one financial virtual community was selected for the study. Although the results of this study were in line with our expectations, the universality of our conclusions deserve further study. In the future, more virtual financial communities should be selected to verify the universality of our conclusions. Secondly, the samples were collected from a virtual financial community that contained fewer senior citizens. This may have a certain impact on the results. In addition, the sample size was small. Future research should have larger sample sizes and adjust for other variables. In the future, we intend to continue studying the mechanism of influence of opinion leaders in depth.

\section{Acknowledgement}

Supported by Wealth Management Project of Shandong Technology and Business University (No:2019ZBKY042).

\section{References}

Aiken, L. S., \& West, S. G. (1991). Multiple Regression: Testing and Interpreting Interactions. Newbury Park, CA: Sage.

Alsajjan, B., \& Dennis, C. (2008). Internet banking acceptance model: cross-market examination. Journal of Business Research, 63(9). https://doi.org/10.1016/j.jbusres.2008.12.014

Awad, N. F., \& Ragowsky, A. (2008). Establishing Trust in Electronic Commerce Through the Online Word of Mouth: An Examination Across Genders. Journal of Management Information Systems, 24(4). https://doi.org/10.1016/j.jbusres.2008.12.014

Bagozzi, P., \& Dholakia, M. (2002). Intentional social action in virtual communities. Journal of Interactive Marketing, 16(2), 2-21. https://doi.org/10.1002/dir.10006

Bansal, H. S., \& Voyer, P. A. (2000). Word-of-Mouth Processes within a Services Purchase Decision Context. Journal of Service Research, 3(2), 166-177. https://doi.org/10.1177/109467050032005

Bei, L. T., Chen, E. Y. I., \& Widdows, R. (2004). Consumers' online information search behavior and the phenomenon of search vs. experience products. Journal of Family and Economics Issues, 25(4), 449-467. https://doi.org/10.1007/s10834-004-5490-0

Blazevic, G., Misic, S., \& Simac, M. (2014). Importance of Managing PMO in Croatian PM Market. Procedia Social and Behavioral Sciences, 119, 949-956. https://doi.org/10.1016/j.sbspro.2014.03.106

Bodendorf, R., \& Kaiser, C. (2009). Detecting opinion leaders and trends in online social networks. The $2^{\text {nd }}$ ACM Workshop on social Web Search and Mining. https://doi.org/10.1145/1651437.1651448 
Casalo, L. V., Flavian, C., \& Guinaliu, M. (2011). Antecedents and consequences of consumer participation in online communities: The case of the travel sector. International Journal of Electronic Commerce, 15(2), 137-167. https://doi.org/10.2753/jec1086-4415150205

Chen, Y., \& Liu, X. Y. (2015). Research on identification of opinion leaders based on social network analysis. Information science, 33(04), 13-19+92.

Choi, S. (2015). The two-step flow of communication in Twitter-based public forums. Social Science Computer Review, 33(6), 696-711. https://doi.org/10.1177/0894439314556599

Dellarocas, C., Zhang, X. Q., \& Awad, N. F. (2007). Exploring the Value of Online Product Reviews Forecasting Sales: the Case of Motion Pictures. Journal of Interactive Marketing, 21(4), 23-45 https://doi.org/10.1002/dir.20087

Dessart, L. (2017). Social media engagement: A model of antecedents and relational outcomes. Journal of Marketing Management, 33(5-6), 1-25. https://doi.org/10.1080/0267257X.2017.1302975

Dong, X. S., \& Zhang J. H. (2009). Overview of consumer online interaction tendency. Business times, 12, 18-19.

Du, X. M. (2016). Research on the influence of online reviews on consumers' buying intentions. Management review, 28(03), 173-183.

Frank, T., \& Rothaermel, S. S. (2001). Virtual internet communities and commercial success: Individual and community-level theory grounded in the atypical case of TimeZone.com. Journal of Management, 27. https://doi.org/10.1177/014920630102700305

Gefen, K., \& Straub. (2003). Trust and TAM in Online Shopping: An Integrated Model. MIS Quarterly, 27(1), 51. https://doi.org/10.2307/30036519

Kim, W. G., Lee, C. A., \& Hiemstra, S. J. (2004). Effects of an online virtual community on the customer loyalty and travel product purchases. Tourism Management. https://doi.org/10.1016/s0261-5177(03)00142-0

Lazarsfeld, P., Berelson, B., \& Gaudet, H. (1948). The People's Choice: How the Voter Makes Up His in a Presidential Election. New York: Columbia University Press.

Li, G. X., \& Wang Z. P. (2016). Research on influencing factors of participation motivation and participation intention of supporters of science and technology award crowdfunding. Journal of management, 13(4), 580-587.

Li, M. C., \& Xue, M. M. (2019). An empirical study on influence factors of opinion leaders on brand image construction in virtual community. Modern commercial industry, 40(29), 56-57.

Lin, H. C., Bruning, P. F., \& Swarna, H. (2018). Using online opinion leaders to promote the hedonic and utilitarian value of products and services. Business Horizons, 61(3), 431-442. https://doi.org/10.1016/j.bushor.2018.01.010

Ludwig, S., de Ruyter, K., Friedman, M., Brüggen, E. C., Wetzels, M., \& Pfann, G. (2013). More Than Words: The Influence of Affective Content and Linguistic Style Matches in Online Reviews on Conversion Rates. Journal of Marketing, 1. https://doi.org/10.1509/jm.11.0560

Luqiu, L. R., Schmierbach, M., \& Yu-Leung, N. (2019). Willingness to follow opinion leaders: A case study of Chinese Weibo. Computers in Human Behavior, 101, 42-50. https://doi.org/10.1016/j.chb.2019.07.005

McKnight, D. H., \& Choudhury, V. (2006). Distrust and trust in B2C e-commerce: Do they differ? [C] Proceedings of the 8 international conference on Electronic commerce: The new e-commerce innovations for conquering current barriers, barriers and limitations to conducting successful business on The Internet. ACM, 482-491. https://doi.org/10.1145/1151454.1151527

Moldovan, S., Muller, E., Richter, Y., \& Yom-Tov, E. (2016). Opinion leadership in small group. International Journal of Research in Marketing, 34(2), 536-552. https://doi.org/10.1016/j.ijresmar.2016.11.004

Park, D., Lee, J., \& Han, I. (2007). The effect of negative online consumer reviews on product attitude: An information processing view. Electronic Commerce Research and Applications, 3. https://doi.org/10.1016/j.elerap.2007.05.004

Pavlou, P. A., \& Gefen, D. (2004). Building effective online marketplaces with institution-based trust. Information Systems Research. https://doi.org/10.1287/isre.1040.0015 
Thakur, R., Angriawan, A., \& Summey, J. H. (2015). Technological opinion leadership: The role of The personal innovativeness, gadget is love, and technological innovativeness. Journal of Business Research, 69(8), 2764-2773. https://doi.org/10.1016/j.jbusres.2015.11.012

Van, E., Peter, S., Jager, W., Lee, F., \& Peter, S. H. (2011). Opinion leaders' role in innovation diffusion: A simulation study. The Journal of Product innovation Management. https://doi.org/10.1111/j.1540-5885.2011.00791.x

Wan, C. (2014). Analysis and design of network questionnaire system [D]. Beijing Jiaotong University.

Weimann, G. (1994). The influentials: People who influence people. Albany, NY: State University of New York Press. https://doi.org/10.5860/choice.32-4316

Wen, Z. L. (2005). Comparison and application of moderating effect and mediating effect. Acta psychologica sinica, 02, 268-274.

Wierz, C., \& de Ruyter, K. (2007). Beyond the call of duty: Why customers contribute to firm-hosted commercial online communities. Organization Studies, 28(3), 347-376. https://doi.org/10.1177/0170840607076003

Zaichkowsky, J. K. (1986). Conceptualizing Online interaction propensity. Journal of Advertising, 15(2), 4-14+34. https://doi.org/10.1080/00913367.1986.10672999

Zhou, B. Y. (2010). Research on virtual community construction and interaction based on the perspective of financial institutions. Economist, 10, 71-72.

Zuo, W. M., Wang, X., \& Fan, X. (2014). The relationship between social capital based online public praise and purchase intention in the context of socialized e-commerce. Nankai management review, 17(04), 140-150+160.

\section{Copyrights}

Copyright for this article is retained by the author(s), with first publication rights granted to the journal.

This is an open-access article distributed under the terms and conditions of the Creative Commons Attribution license (http://creativecommons.org/licenses/by/4.0/). 